\title{
Production of a Curve Number map using GIS Techniques in the watershed of the high Sebou (Morocco)
}

\author{
BtissamJabri ${ }^{1, *}$, Mohammed Abdelbaset Hessane ${ }^{1}$ \\ ${ }^{1}$ Laboratoire Géodynamique et Ressources Naturelles (LGRN), Faculté des Sciences Dhar El Mahraz Fès, Université Sidi Mohamed \\ Ben Abdellah, B.P. 1796 Fès-Atlas,30003 MAROC
}

\begin{abstract}
This work focusing on the collection and preparation of necessary data for hydrological modeling of High Sebou watershedupstream of the dam Allal El Fassi. It describes a methodology for combining space technologies, including geographical information systems (GIS), remote sensing and digital terrain models (DTM), with hydrological models with a view to prepare for a spatial hydrologic modeling whose used for flood forecasting.

The methodology for conducting this study comes in several parts:

The collection and processing of geographic data constituted the first part of this project. This approach is, in the beginning, to automatic extraction of sub-basins and drainage network, then the formatting of data for the mapping of the basin and finally, the preparation of the land use and soil for the development of a map of Curve Number $(\mathrm{CN})$.
\end{abstract}

\section{Introduction}

Over the last twenty years, Morocco has experienced several tragic flood events that have caused floods in several parts of the country.

Like the other basins of the Kingdom, the Sebou watershed has experienced catastrophic floods in the past, causing enormous economic and sometimes even human damage.

The comprehensive inventory of sites at risk of flooding in the Sebou watershed, carried out as part of the National Flood Protection Plan and supplemented by the provincial flood control commissions, made it possible to retain 109 sites. at risk of flooding [1].

The work presented in this article concerns the watershed of High Sebou which experienced catastrophic floods, like that of the flood of October 10, 2008 of Oued Sebou[1].The High Sebou watershed was the scene of this exceptional hydrological phenomenon recorded the largest flood in its history is $2600 \mathrm{~m} 3 / \mathrm{s}$. The purpose of the work is to collect and prepare the necessary data for the development of a spatial hydrological model on the basis of the HEC-HMS hydrological model,based on the functionalities offered by geographic information systems (GIS) and remote sensing.

\subsection{Presentation of the Study Area}

The study area (Figure 1) is located in the high part of the large basin of the Oued Sebou. It is located between latitudes $33^{\circ}$ and $34^{\circ}$ north and longitudes $4^{\circ}$ 03 "and $5^{\circ} 20^{\prime}$ "west and covers an area of $5709 \mathrm{~km} 2$. This watershed is drained by the Sebou wadi which originates in the region of Aguelmane Sidi Ali at about $2078 \mathrm{~m}$ altitude[4]. 

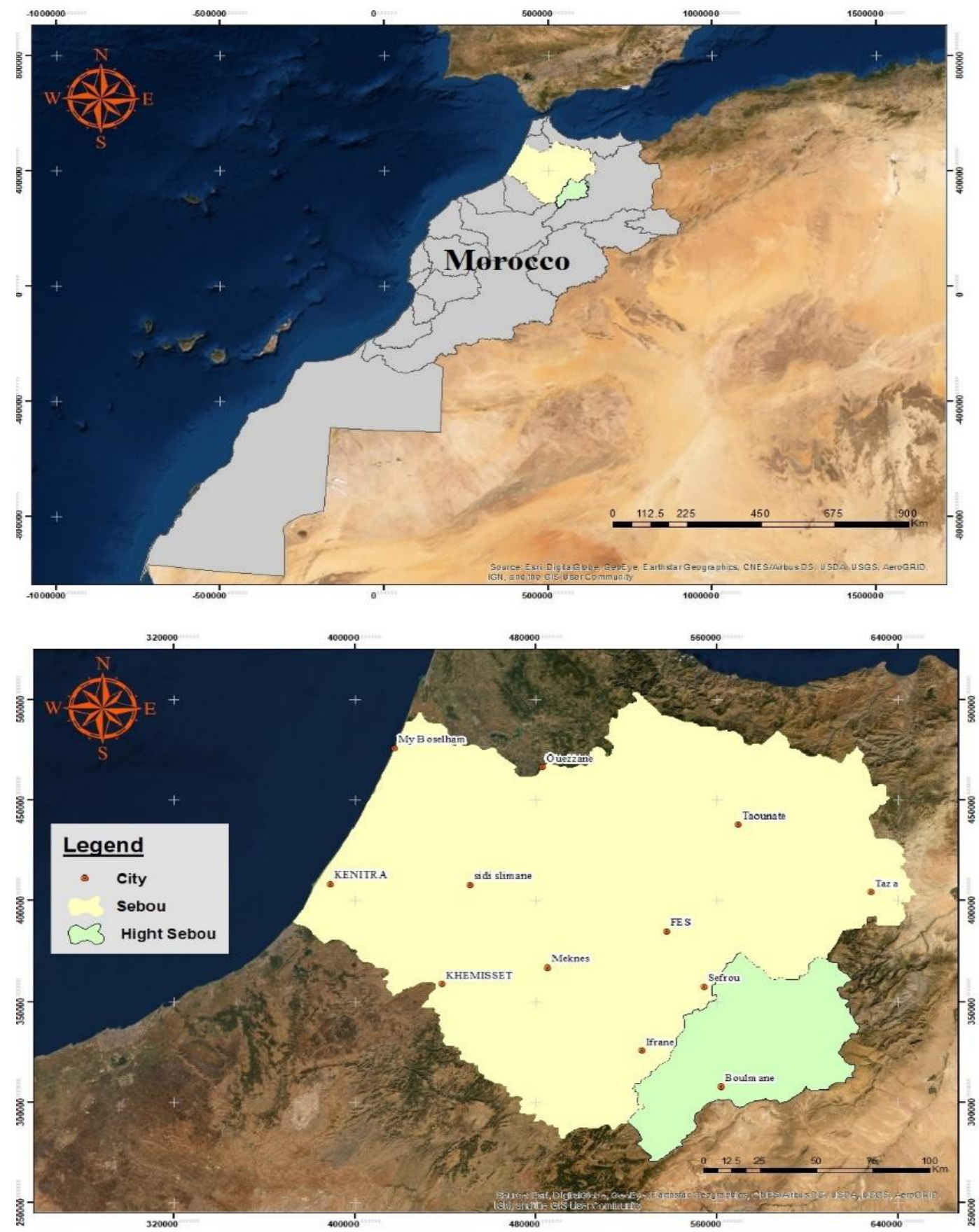

Fig. 1. Map of the geographical location of the High Sebou watershed

\section{Materials and methods}

Several software have been used in the framework of our study:

- $\quad$ Software ArcGIS: is a geographic information system (GIS) for working with maps and geographic information. It is used for creating and using maps, compiling geographic data, analyzing mapped information, sharing and discovering geographic information, using maps and geographic information in a range of applications, and managing geographic information in a database.
We chose to use ArcGIS for data preparation, and for its ability to process spatialdata only for its compatibility with HECHMS software.

- $\quad$ Arc Hydro: is a set of data models and tools that work in ArcGIS to support geospatial and temporal data analysis.

- $\quad$ ERDAS Imaging: is a software dedicated to the processing, the spatial imaging analysis and the extraction of information from these images, especially for remote sensing and GIS. ERDAS is developed by the Swiss company Leica Geosystems.

ERDAS Imagine will be used as part of this project for the mosaic of DTM filesto cover the study area, and

Btissam Jabri :btissamjabri@gmail.com 
alsofor the supervised classification of the satellite image in order to elaborate the land use map.

- HEC-HMS: is a Hydrologic Modeling System that is designed to describe the physical properties of river basins, the meteorology that occurs on them, and the resulting runoff and streamflow that are produced. This model is produced by the Hydrologic Engineering Center of the US Army Corps of Engineers in Davis[7].

- HEC-GEOHMS: is a coupling of HEC-HMS, and ArcGIS: This coupling facilitates the entry of the datafor the modelling in HEC-HMS[6].

The coupling between the two HEC-GeoHMS software and HEC-HMS makes it possible to translate

\section{Results and discussion}

\section{1 preparation of spatial input data of the model}

\subsubsection{Delineation of the Hight Sebou watershed from ASTER GDEM}

The DTM used is ASTER GDEM (Advanced Spaceborne Thermal Emission and Reflection Radiometer - Global Digital Elevation Model).The altimetric resolution of this model is $30 \mathrm{~m}$, and its altimetric accuracy between 5 and $20 \mathrm{~m}$.Arc hydro tools in ArcGIS software, was used to extract drainage channels through Arc Hydro. The delineation of the watershed is followed by running the following functions (figure 2): Fill, flow accumulation, Flow direction, Stream definition, Stream Segmentation, Catchment Grid Delineation, Catchment Polygon, Drainage line, Adjoint Catchment processing and Drainage point [5].

\subsubsection{Morphological characteristics of sub- watersheds}

The calculation of the characteristics of subwatersheds is done by HEC-GeoHMS, the area, the perimeter, the longest flow-path, the time of concentration and the storage coefficient of the sub-watersheds. These characteristics are presented in Table 1.

Figure 3 shows the longest flowpath of each subwatershed, calculated by HEC-GeoHMS. the spatial information of the GIS into hydrological information. This information can be stored in distributed form in space, in a grid whose grid is defined (Gridded Hydrologic Data).

Indeed, HEC-GeoHMS operates in the DTM via GIS to achieve sub-watershed delineation and automatic watershed extraction (Watershed \& River Characteristics). Then it allows to estimate the hydrological parameters to enter the model (HMS Inputs) like the concentration time, the longest flowpath, etc.

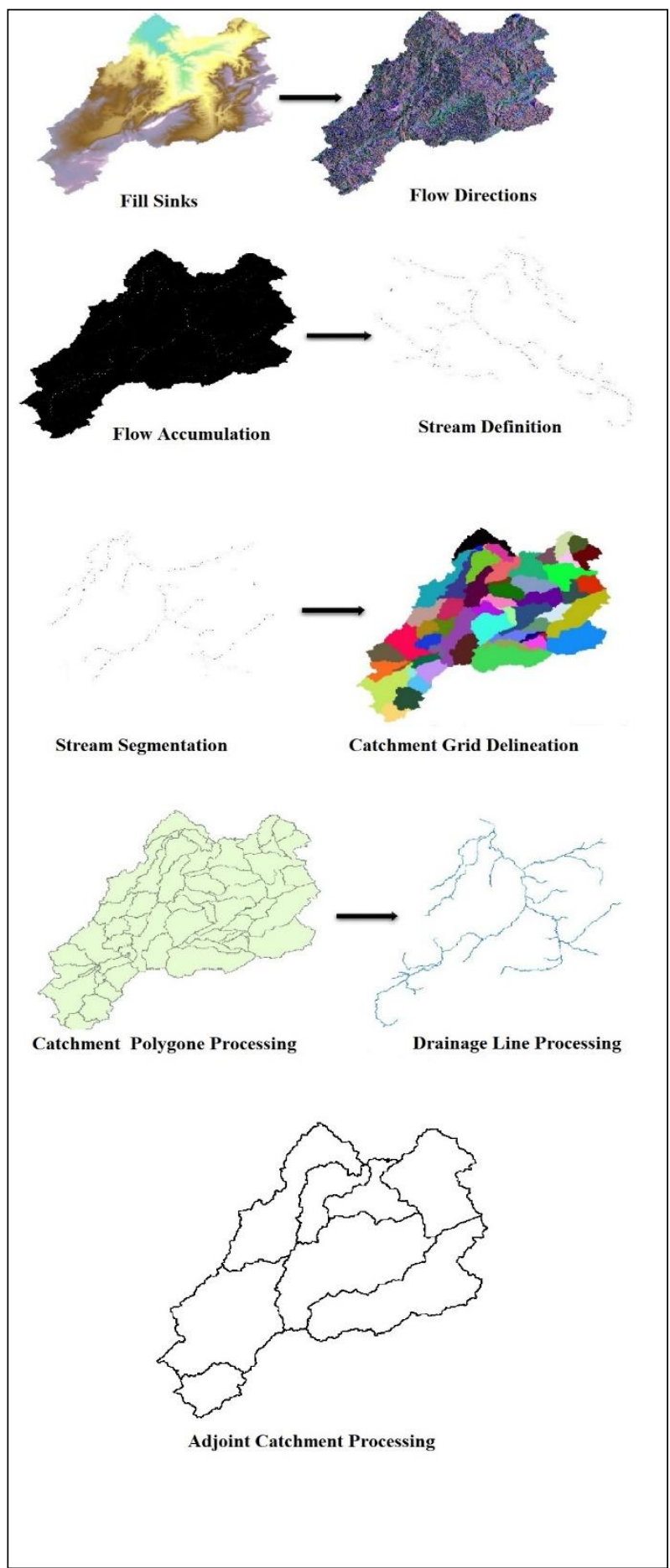


Fig. 2. The delimitation steps of the sub-watershed by the Arc-Hydro tool

Table 1 :Characteristics of sub-watersheds

\begin{tabular}{|c|c|c|c|c|c|c|c|}
\hline $\begin{array}{c}\text { sub- } \\
\text { watershed }\end{array}$ & $\begin{array}{c}\text { area } \\
(\mathrm{km} 2)\end{array}$ & $\begin{array}{l}\text { perimeter } \\
(\mathrm{Km})\end{array}$ & $\begin{array}{c}\text { the } \\
\text { longest fl } \\
\text { ow-path } \\
\text { (km) }\end{array}$ & Hmax & Hmin & $\begin{array}{l}\text { time of con } \\
\text { centration } \\
\text { (hour) }\end{array}$ & $\begin{array}{c}\text { the storage } \\
\text { coefficient } \\
\text { (hour) }\end{array}$ \\
\hline Ain Sebou & 308.27 & 168.74 & 31.24 & 2228 & 640 & 2.94 & 4.79 \\
\hline $\begin{array}{c}\text { Ait } \\
\text { Khabbach }\end{array}$ & 1061.50 & 268.31 & 66.44 & 2460 & 1466 & 8.44 & 13.76 \\
\hline $\begin{array}{l}\text { Allal Al } \\
\text { Fassi }\end{array}$ & 757.92 & 301.85 & 84.34 & 2051 & 385 & 9.11 & 14.85 \\
\hline Azzaba & 310.91 & 170.11 & 46.82 & 1837 & 474 & 4.98 & 8.12 \\
\hline $\begin{array}{l}\text { Dar El } \\
\text { Hamra }\end{array}$ & 663.76 & 189.27 & 43.84 & 3070 & 756 & 3.77 & 6.14 \\
\hline El Mers & 982.37 & 293.01 & 58.27 & 3071 & 1221 & 5.71 & 9.31 \\
\hline $\begin{array}{l}\text { Pont Ait } \\
\text { Aissa }\end{array}$ & 248.41 & 117.59 & 28.52 & 2416 & 1883 & 4.03 & 6.57 \\
\hline Pont Mdez & 1130.69 & 261.98 & 68.75 & 2800 & 732 & 6.62 & 10.79 \\
\hline
\end{tabular}

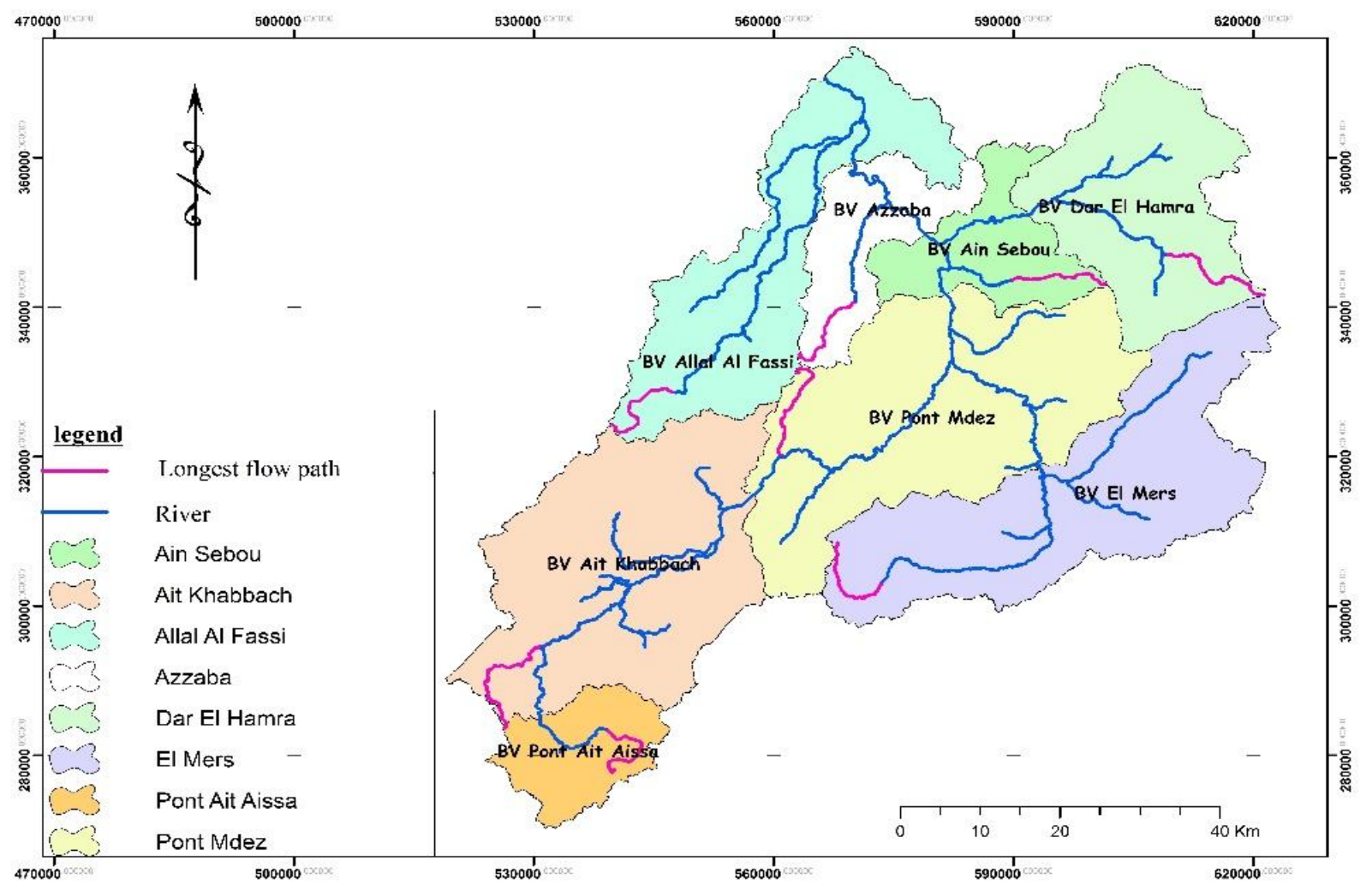

Fig. 3.longest flowpath of each sub-watershed

\subsubsection{Land use map}

Land use map was generated from Landsat ETM+ (Enhanced Thematic Mapper), data from 2005 with a resolution of $30 \mathrm{~m}$. The supervised classification method was used for classification of images using the ERDAS software. The watershed of High Sebou is classified into 4 classes as shown in Figure 4.

Btissam Jabri :btissamjabri@gmail.com 


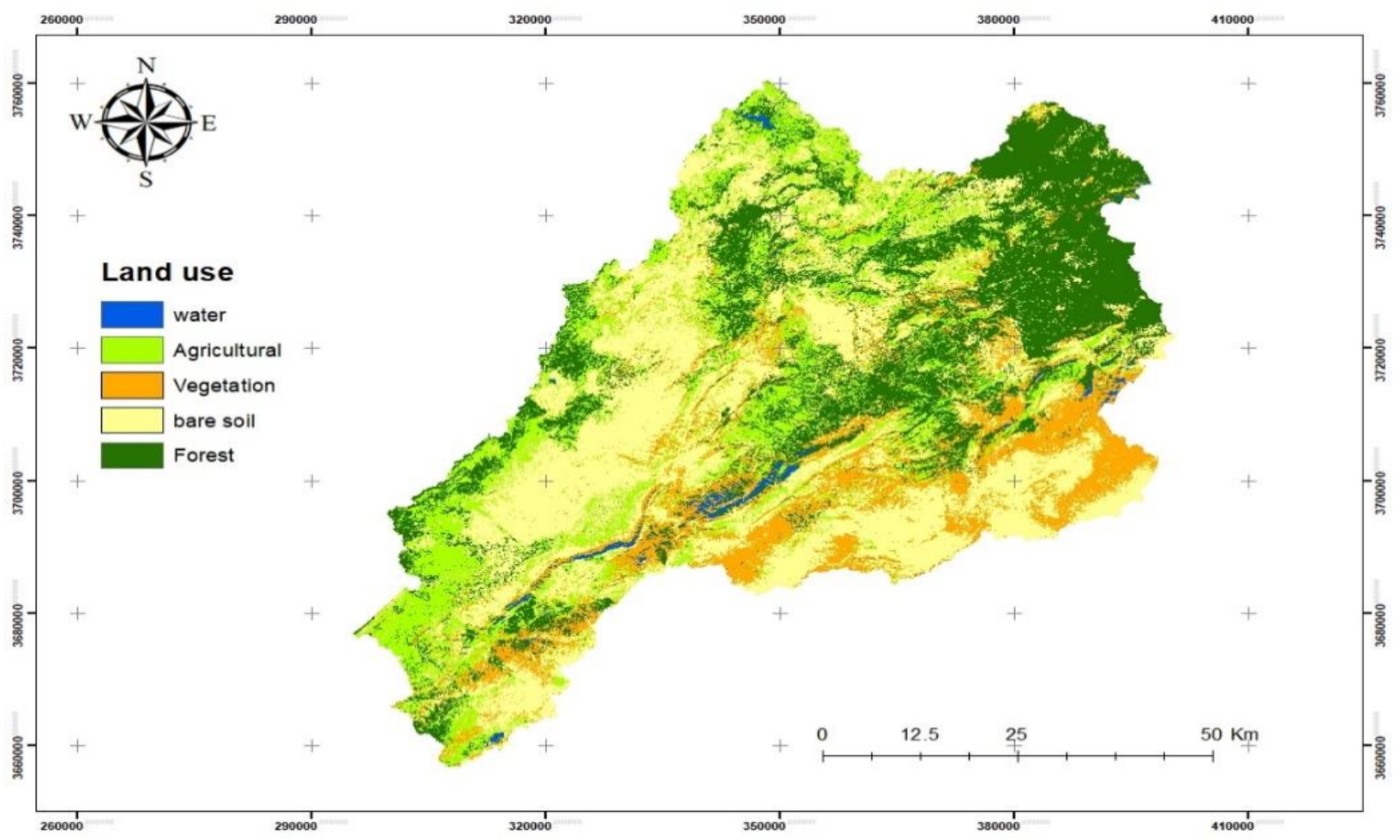

Fig.4.Basin Land use types

\subsection{4 soil data processing}

The nature of the soil affects the rate of rise of floods and their volume.
A basic soil type map, according to the soil classification, was retrieved from the Fez Water and Forestry Directorateas an image that we digitized using ArcGIS software to obtain a digitized map (Figure 5).

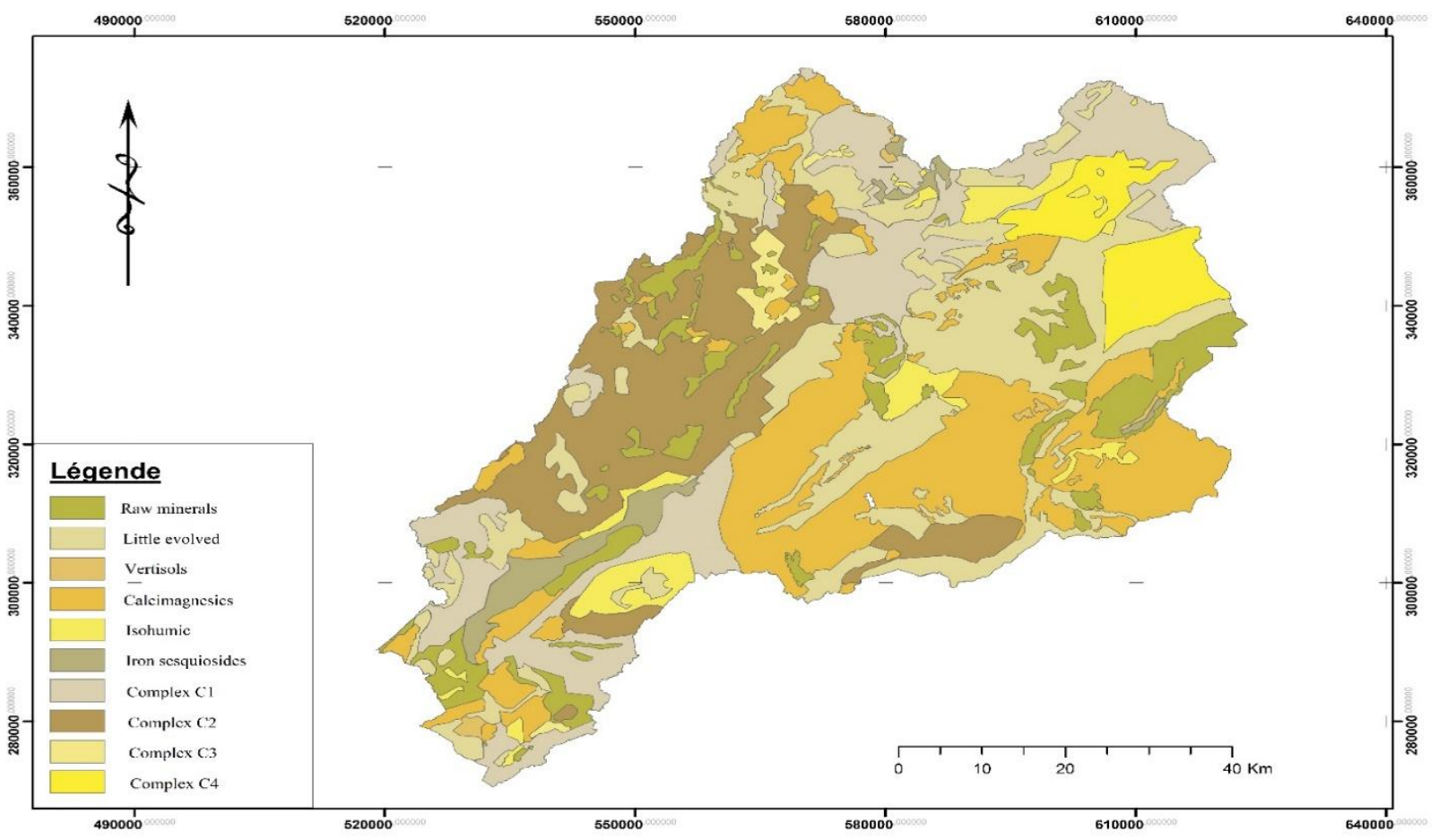

Fig.5. Dominant soils in the high Sebou basin

Btissam Jabri :btissamjabri@gmail.com 


\subsubsection{Hydrologic soil groups map soil data processing}

Soils are classified into hydrologic soil groups (HSG's)to indicate the minimum rate of infiltration obtained forbare soil after prolonged wetting. The HSG's, which areA, B, C, and D are one element used in determining runoff curve numbers. The fourgroups are defined by SCS soil scientists asfollows[8]:

- Group A: soils have low runoff potential and high infiltrationrates even when thoroughly wetted. They consistchiefly of deep, well to excessively drained sand orgravel and have a high rate of water transmission.

- $\quad$ Group B soils have moderate infiltration rates whenthoroughly wetted and consist chiefly of moderatelydeep to deep, moderately well to well drained soils withmoderately fine to moderately coarse textures.
- $\quad$ Group C: soils have low infiltration rates when thoroughlywetted and consist chiefly of soils with a layerthat impedes downward movement of water and soilswith moderately fine to fine texture.

- $\quad$ Group D: soils have high runoff potential. They havevery low infiltration rates when thoroughly wetted andconsist chiefly of clay soils with a high swelling potential,soils with a permanent high water table, soils with aclaypan or clay layer at or near the surface, and shallowsoils over nearly impervious material.

The Figure 8 presents the Soil map of the high Sebou obtained according to the hydrological classification, the most dominant class is Class A, which shows that soils have high infiltration rates.

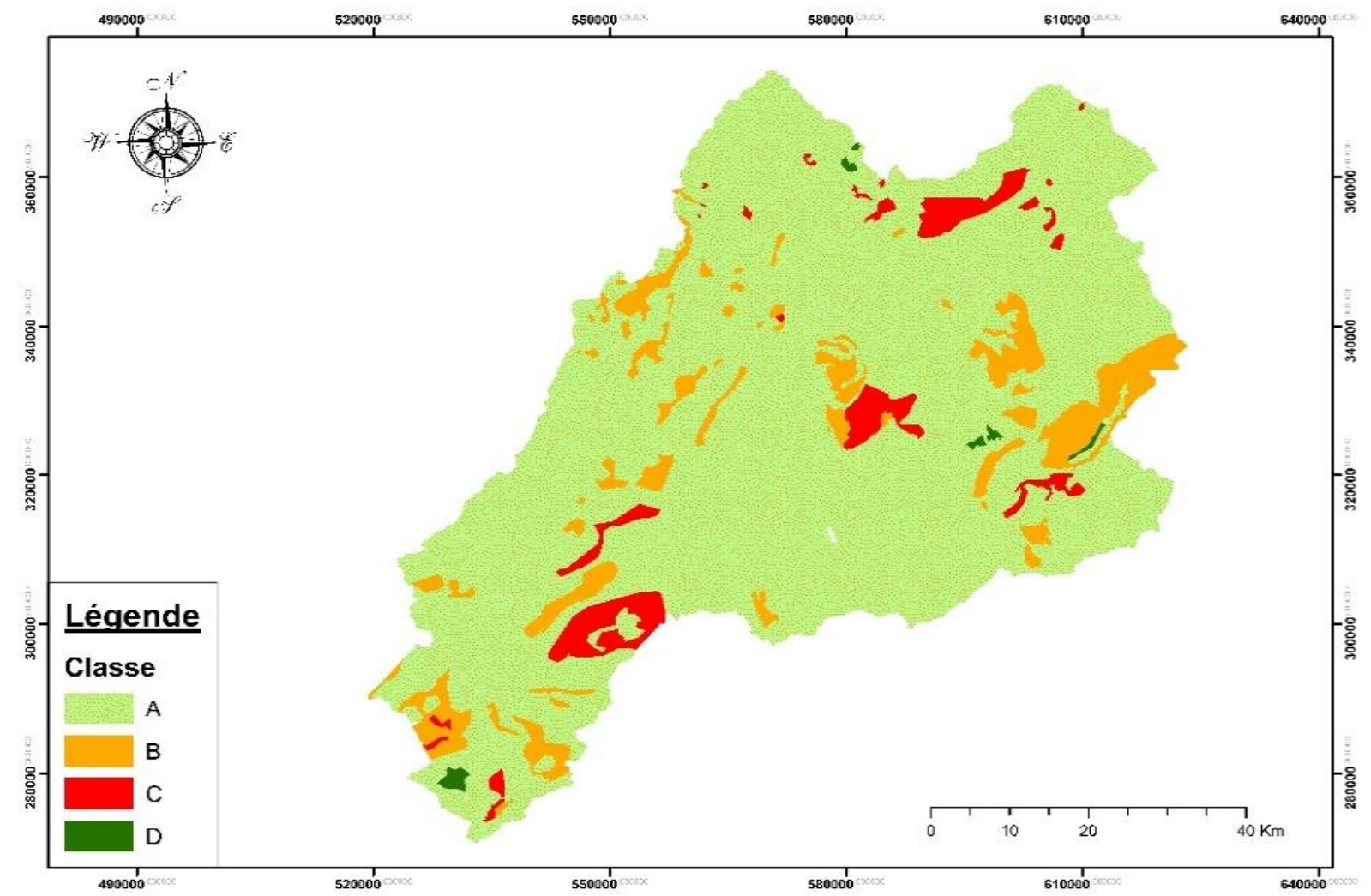

Fig.6. Hydrologic soil groups of Hight Sebou watershed

\subsection{Calculation of curve number}

The SCS curve number method (SCS, 1972), was based on an empirical equation that estimates land use and soil type. The $\mathrm{CN}$ is used to compute the volume of rainfall excess in the HEC-HMS and is therefore used as the description of watershed soil and land use characteristics in this modeling study.

The Curve number is calculated in ArcGIS trough the union processing attributes combined to one of the lands and Hydrological soil groups. Using the SCS TR55 report from 1986, the creation of the $\mathrm{CN}$ table that has curve numbers values for different combinations of soil hydrologic groups and land uses has been made as shown in the table below:

Table 2: CN Lookup table

\begin{tabular}{|c|c|c|c|c|c|}
\hline LUvalue & Description & A & B & C & D \\
\hline $\mathbf{1}$ & Water & 100 & 100 & 100 & 100 \\
\hline $\mathbf{2}$ & Forest & 30 & 58 & 71 & 78 \\
\hline $\mathbf{3}$ & Agricultural & 67 & 77 & 83 & 87 \\
\hline $\mathbf{4}$ & Vegetation & 49 & 69 & 79 & 83 \\
\hline $\mathbf{5}$ & baresoil & 68 & 79 & 86 & 89 \\
\hline
\end{tabular}




\subsection{Generation of curve number}

The Curve number is generated in ArcGIS through the union between the land use, the soil, the table of
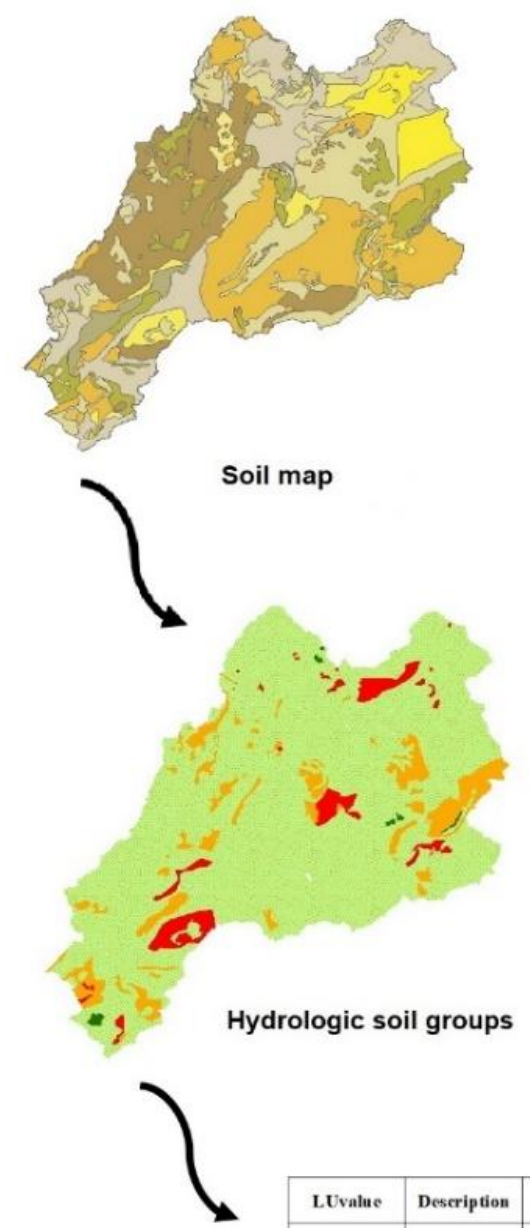

\begin{tabular}{|c|c|c|c|c|c|}
\hline LUvalue & Description & A & B & C & D \\
\hline $\mathbf{1}$ & Water & 100 & 100 & 100 & 100 \\
\hline $\mathbf{2}$ & Forest & 30 & 58 & 71 & 78 \\
\hline $\mathbf{3}$ & Agricultural & 67 & 77 & 83 & 87 \\
\hline $\mathbf{4}$ & Vegetarion & 49 & 69 & 79 & 83 \\
\hline $\mathbf{5}$ & bare soil & 68 & 79 & 86 & 89 \\
\hline
\end{tabular}

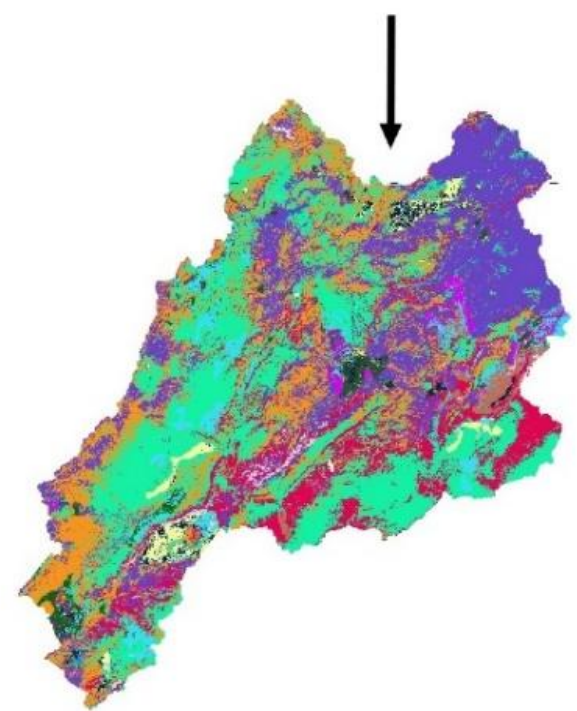

Fig. 7.Steps to create the Curve Number grid

\footnotetext{
Btissam Jabri :btissamjabri@gmail.com
}

Curve Number, and the DTM of the basin. The Figure 9 shows the different steps of creating the Curve number grid.
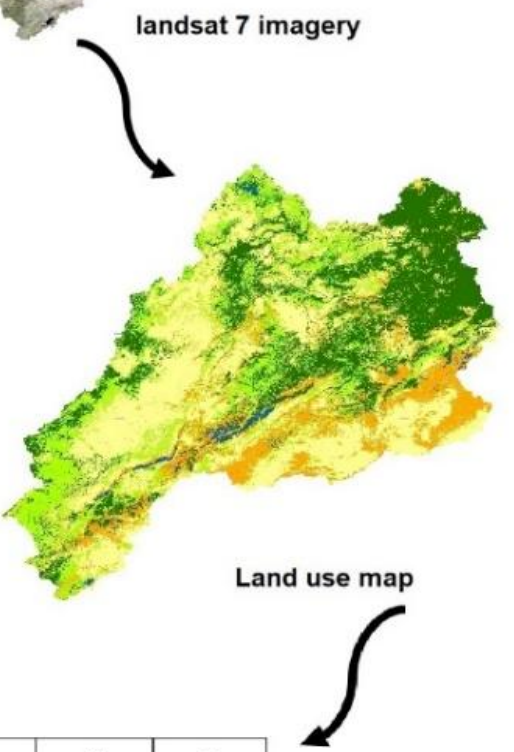
The value of the Curve Number depends on the hydrological group of the soil, the land use and the initial moisture conditions, its value vary between 100 and $30[1]$.
The mapping analysis shows that most soils in the high Sebou watershed are highly permeable and have high infiltration potential. (Figure 8).

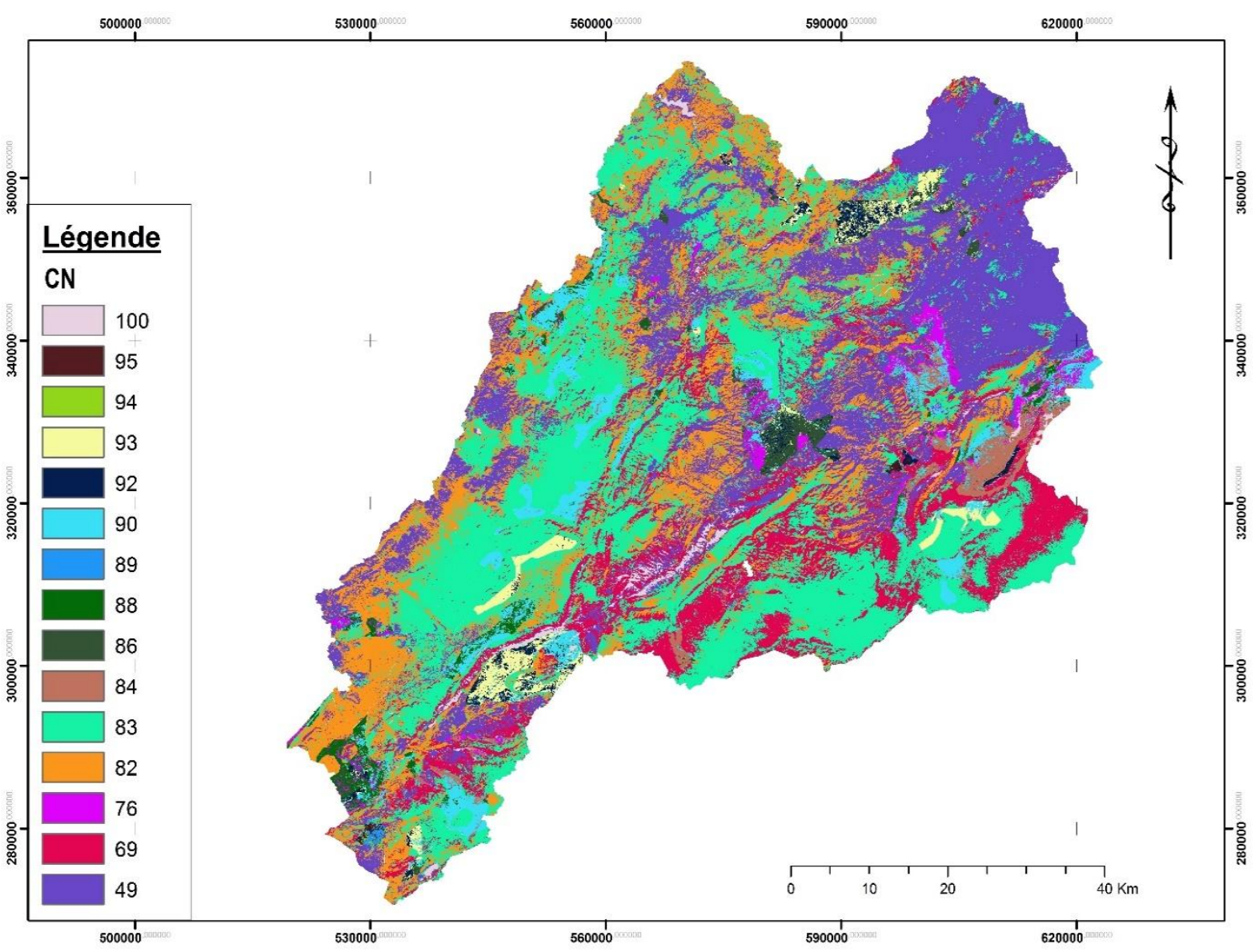

Fig. 8. Curve number map of the Hight Sebou watershed

\section{Conclusion}

The rapid development of remote sensing and geographic information systems (Arc-Hydro and HECGeoHMS) has greatly improved the interpretation and use of spatial data quantitatively and qualitatively in different directions, particularly in hydrological modeling.

In this context, a method of modeling, reflecting as best as possible the reality of the field is sought. The methodology used consists of the use of geographic information systems and remote sensing to construct the

\section{References}

1. A. Benkka, M. Ouadgiri, Modélisation hydrologique spatialisée du bassin versant de l'Oued El Maleh, (2013)

2. ABHS, Etude d'actualisation du plan directeur d'aménagement intègre des ressources en eau du bassin hydraulique de Sebou, septembre (2006). geometry of the basin model and calculate its parameters.

In this work we have finally demonstrated the role of remote sensing in extracting the land use map and the capacity of the Arc-Hydro and HEC-GeoHMS hydrological models in the delimitation of sub-basins, the extraction of the hydrographic network and production of a Curve Number mapthat has been used successfully forestimate surface runoff from thewatershed of high Sebou.

By analyzing the runoff zone, it can be seenthatmost of the values recorded on the curve number map are low which means that the basin layers are permeable with low runoff potential.

3. Direction des Eaux et Forêt Fès, Evaluation de l'érosion et de ses conséquences du bassin versant à l'amont du barrage Allal El Fassi,Décembre (1997)

4. Direction des Eaux et Forêt Fès, Milieu physique et socio économie $d u$ bassin versant à l'amont $d u$ barrage Allal El Fassi,Décembre (1997) 
5. I.Khaddor, A.Hafidi Alaoui,Production of a Curve Number map for Hydrological simulation - Case study: KalayaWatershed located in Northern Morocco,pp. 1691-1699,9(4),December (2014).

6. USACE United States Army Corps of Engineers, HEC-GeoHMS Geospatial Hydrologic Modeling Extension, Technical Reference Manual, Davis, CA 95616 USA, CPD-77, May (2009)

7. USACE United States Army Corps of Engineers, Hydrologic Modeling System HEC-HMS, Technical Reference Manual, Davis, CA 95616 USA, CPD74A, April (2008)

8. USDA,Technical Release 55,June (1986)

9. V.Merwade, Creating SCS Curve Number Grid using HEC-GeoHMS, School of Civil Engineering, Purdue University, September (2012) 